\title{
Denosumab for management of refractory hypercalcaemia in recurrent parathyroid carcinoma
}

\author{
K Nadarasa*, A Theodoraki ${ }^{1, *}$, T R Kurzawinski ${ }^{2}$, R Carpenter, J Bull ${ }^{3}$, \\ T T Chung ${ }^{1}$ and W M Drake
}

Department of Endocrinology, St Bartholomew's Hospital, London, UK, 'Department of Diabetes and Endocrinology, UCLH NHS Foundation Trust, London, UK, ${ }^{2}$ Department of Endocrine Surgery, UCLH NHS Foundation Trust, London, UK and ${ }^{3}$ Department of Neurosurgery, The Royal London Hospital, London, UK

*(K Nadarasa and A Theodoraki contributed equally to this work)
Correspondence should be addressed to W M Drake Email

w.m.drake@qmul.ac.uk
We read with interest the report by Karuppiah et al. (1) on the use of high-dose denosumab for the treatment of refractory hypercalcaemia secondary to parathyroid carcinoma. Our group has also successfully used this therapy in similar clinical circumstances.

A 77-year old man presented with recurrent hypercalcaemia (corrected serum calcium $2.73 \mathrm{mmol} / \mathrm{l}$, normal 2.2-2.6) and a raised serum parathyroid hormone (PTH) of $16 \mathrm{pmol} / \mathrm{l}$ (normal 1.1-6.9), consistent with disease recurrence, 2 years after excision of a malignant parathyroid lesion. There was no evidence, either by ultrasound or nuclear medicine imaging, of recurrent disease in the neck, but CT scanning showed a right paratracheal nodule and three discrete lung nodules in keeping with pulmonary metastases. In the following 3 months, the hypercalcaemia deteriorated (peak corrected calcium $3.35 \mathrm{mmol} / 1$ requiring hospital admission for control of symptoms), but there was little response to cinacalcet or repeated infusions of bisphosphonates. Denosumab $120 \mathrm{mg}$ was commenced and continued monthly. Within 4 days the corrected serum calcium had fallen from 3.14 to $2.74 \mathrm{mmol} / \mathrm{l}$ and has remained at this level for 4 months without recourse to hospital admission.

A 48-year-old man developed recurrent hyperparathyroidism (corrected serum calcium $4.22 \mathrm{mmol} / \mathrm{l}$, serum PTH $145 \mathrm{pmol} / \mathrm{l}) 2$ years after excision of a large, invasive parathyroid carcinoma followed by adjunctive external beam neck radiotherapy. He had previously undergone resection of an ossifying fibroma of the maxilla, and genetic analysis was in keeping with a diagnosis of hyperparathyroidism jaw tumour syndrome. There was no evidence of disease recurrence in the neck, but nuclear medicine and magnetic resonance imaging revealed uptake of sestaMIBI into a soft tissue osseous-based lesion in the T8 vertebra. Hypercalcaemia was refractory to fluid resuscitation, high-dose bisphosphonates and cinacalcet, so he was treated with a single dose of denosumab $120 \mathrm{mg}$. Within a week, the corrected serum calcium level fell to $2.46 \mathrm{mmol} / \mathrm{l}$ and he underwent resection of what, at present, appears to be a solitary skeletal metastasis. He remained well and required a low dose of alfacalcidol to maintain normocalcaemia.

As Karuppiah et al. (1) point out in their report, patients with parathyroid carcinoma rarely succumb to 'cancer cachexia' but, historically, have died of the complications of hypercalcaemia (2). Against this background, the known (albeit modest) risk of complications of repeated high-dose bisphosphonate infusions makes the emerging efficacy of denosumab in this clinical situation an important additional therapeutic option $(3,4)$. Formal clinical studies in this area are improbable, so evidence has to be accumulated from anecdotal reports $(1,4,5)$. Our purpose here is to add to the published world experience and, accepting the paucity of long-term data, endorse its availability as a potential option for the treatment of refractory hypercalcaemia in this challenging disease.

Declaration of interest

The authors declare that there is no conflict of interest that could be perceived as prejudicing the impartiality of the research reported.
(C) 2014 European Society of Endocrinology Printed in Great Britain
Published by Bioscientifica Ltd. 
Funding

This research did not receive any specific grant from any funding agency in the public, commercial or not-for-profit sector.

\section{References}

1 Karuppiah D, Thanabalasingham G, Shine B, Wang LM, Sadler GP, Karavitaki N \& Grossman AB. Refractory hypercalcaemia secondary to parathyroid carcinoma: response to high-dose denosumab. European Journal of Endocrinology 2014171 K1-K5. (doi:10.1530/ EJE-14-0166)
2 Wei CH \& Harari A. Parathyroid carcinoma: update and guidelines for management. Current Treatment Options in Oncology 201213 11-23. (doi:10.1007/s11864-011-0171-3)

3 Ruggiero SL, Mehrotra B, Rosenberg TJ \& Engroff SL. Osteonecrosis of the jaws associated with the use of bisphosphonates: a review of 63 cases. Journal of Oral and Maxillofacial Surgery 200462 527-534. (doi:10.1016/ j.joms.2004.02.004)

4 Bowyer SE, White AM, Ransom DT \& Davidson JA. Resistant hypercalcaemia in metastatic parathyroid carcinoma. Medical Journal of Australia 2013198 559-561. (doi:10.5694/mja12.11243)

5 Vellanki P, Lange K, Elaraj D, Kopp PA \& El Muayed M. Denosumab for management of parathyroid carcinoma-mediated hypercalcemia. Journal of Clinical Endocrinology and Metabolism 201499 387-390. (doi:10.1210/jc.2013-3031)

Received 13 June 2014

Accepted 17 June 2014 